\title{
Comparison of Usage and Effectiveness between Methoxy Polyethylene Glycol Epoetin Beta and Darbepoetin Alfa with Hemodialysis Patients
}

\author{
Jiyeong Yoon ${ }^{1,2}$, Beung Koo Lee ${ }^{1}$, Hyesun Gwak ${ }^{1}$, Jeongmee $\mathrm{Kim}^{2}$ and Youngmee Lee ${ }^{2}$ \\ 1. Ewha Graduate School of Clinical Pharmacology, 52 Ewhayeodae-gil, Seodaemun-gu, Seoul KSO13, Korea \\ 2. Samsung Medical Center, 81 Irwon-Ro Gangnam-gu, Seoul KSO13, Korea
}

\begin{abstract}
Methoxy polyethylene glycol epoetin beta which has a long half-life is developed to provide stable control of hemoglobin levels at extended administration intervals compared to darbepoetin alfa. The purpose of this study was to compare the patterns of use, efficiency of therapy and cost with undergoing hemodialysis patients. Electronic medical record system was used to examine administration frequency, hemoglobin response rate, achievement of target hemoglobin, drug costs. Administration frequency was once in 4 weeks with methoxy polyethylene glycol epoetin beta group and 3 times in 4 weeks with darbepoetin alfa group. Hemoglobin response rate was $61.5 \%$ in methoxy polyethylene glycol epoetin beta at the time of 16 weeks. It was not significantly different from $66.7 \%$ in darbepoetin alfa $(P=1.000)$. The drug cost for methoxy polyethylene glycol epoetin beta group was little higher than darbepoetin alfa group. However, there was no statistically significant difference $(P=0.164)$. Use of methoxy polyethylene glycol epoetin beta is as effective and safe as darbepoetin alfa managing renal anemia in hemodialysis patients. Methoxy polyethylene glycol epoetin beta's extended administration interval improve patient's compliance and enable effective anemia treatment.
\end{abstract}

Key words: Methoxy polyethylene glycol epoetin beta, erythropoiesis stimulating agent, renal anemia, hemoglobin.

\section{Introduction}

Anemia is a common complication of chronic renal failure. Anemia decreases the oxygen supply to the use of tissue, the cardiac output increases as the compensation mechanism, and thereby expansion of the heart, left ventricular hypertrophy is displayed. In severe cases, It may cause cardiac complications such as angina pectoris, congestive heart failure $[1,2]$. Common symptoms of anemia are tiredness, shortness of breath, dizziness, headache, difficulty concentrating, sleep disorders, and symptoms include bleeding disorders, immune and cognitive dysfunction, distal blood circulation disorders appear.

Cause of anemia in chronic renal failure patients will

Corresponding author: Beung Koo Lee, Ph.D., professor, research field: pharmacy practice and science. E-mail:bklee@ewha.ac.kr.

Hyesun Gwak, Ph.D., professor, research field: clinical pharmacology. E-mail: hsgwak@ewha.ac.kr. gradually decrease as height of EPO (erythropoietin) production decreased renal function. Therefore ESA (erythropoiesis-stimulating agent) is the standard treatment for patients with chronic renal anemia [3]. ESA has developed what can be intravenous or subcutaneous injection has been prescribed to patients themselves abdomen, arms, thigh and injected subcutaneously. EPO, is endogenous growth factor secreted by the kidneys about $90 \%$, stimulates the proliferation and differentiation of red blood cell precursors and induces the production of red blood cells. In addition, they cause stimulated emission of red blood cells from the bone marrow.

ESA first introduced to the market is a recombinant human EPO in EA (epoetin alfa) with a glycoprotein of 165 amino acids and peptide bond. EA is constantly used. However, the major limitation is that it is usually administered by injection two or three times per week [4]. DA (darbepoetin alfa) formulations have been 
developed by replacing the 5-amino acid to create new two N-linked glycosylation [5-7]. DA has three times the longer half-life (25.3 hours during intravenous, 48.8 hours during subcutaneous injections) than EA. However, conventional ESA (erythropoiesis stimulating agent) with EA or DA to manage anemia in CKD (chronic kidney disease) patients requires frequent administration, dose changes, and close monitoring of hemoglobin concentration to maintain target hemoglobin levels $[6,7]$.

MPG-EPO (methoxy polyethylene glycol epoetin beta) is a new agent that has a different interaction with the receptor $[8,9]$ unlike the prior formulations with a longer half-life (approximately 130 hours) [10]. MPG-EPO is integrated through amide bonds of the $\mathrm{N}$-terminal amino group or $\varepsilon$-amino group. Therefore, slow association and quick dissociation enables the stimulation of continued erythropoiesis [11]. Due to these different pharmacological characteristics, MPG-EPO was administered to enable a long interval. MPG-EPO is approved for once-monthly maintenance therapy for anemia in patients with chronic kidney disease. Korea has been introduced in 2009, usage is on the rise [12-18].

There is Phase III study about the efficacy and safety of treatment of anemia using the MPG-EPO through comparison with the reaction rate of hemoglobin compared EA. However, study is not compared with DA having a longer half-life and has been developed since the EA.

The purpose of this study was to compare the patterns of administration frequency, hemoglobin response rate, achievement of target hemoglobin and cost during 16 weeks with CKD patients between DA and MPG-EPO group undergoing hemodialysis in Korea.

\section{Materials and Methods}

\subsection{Study Participants}

Patients were screened at Samsung medical center in Korea from April 2011 to October 2012, undergoing hemodialysis more than 16 weeks and were all over 18 years old. To be included in the study, patients must have had hemoglobin concentration less than $11 \mathrm{~g} / \mathrm{dL}$ before starting drug administration. Patients have been prescribed MPG-EPO or DA during study period. Patients were excluded from this study if they had no records about administration. A total of 48 patients were screened at Samsung medical center undergoing hemodialysis more than 16 weeks and were all over 18 years old. 26 patients have been prescribed MPG-EPO or DA during study period. 4 patients with no test results were excluded. Therefore MPG-EPO group was 13 patients, DA group was 9 patients.

The retrospective study was approved by Samsung medical center institutional review board (IRB No.201305055001). This research received no specific grant from any funding agency in the public, commercial, or not-for-profit sectors.

\subsection{Procedures}

Electronic medical record system was used to examine patient characteristics; age, gender, weight, height, diagnosis, underlying disease, lab data; Scr (serum creatinine), Hct (hematocrit), serum ferritin, TIBC (total iron binding capacity), TSAT (transferin saturation), serum iron, i-PTH, whether taking oral iron therapy. In addition, administration frequency, hemoglobin response rate, and achievement of target hemoglobin for each time point $(4,8,12,16$ weeks) were investigated; if the clinical test results do not hold true in the exact interval used as a final measure of the nearest day. High frequency of adverse events; hypertension, diarrhea, nose throat, headache, upper respiratory tract infection whether expressed and drug costs were irradiated [16].

Response rate was defined as the proportion of patients who were examined elevated concentrations above $1.0 \mathrm{~g} / \mathrm{dL}$ from baseline [19].

Achievement of hemoglobin was based on NKF-K/DOQI (national kidney foundation kidney disease outcome quality initiative) guideline in 2007; target hemoglobin concentration equals from 11.0 to 
$12.0 \mathrm{~g} / \mathrm{dL}$ and Korea national HIRA (health insurance and assessment services) criteria; applicable insurance hemoglobin concentration equals from 10.0 to 11.0 $\mathrm{g} / \mathrm{dL}$. This study analyzed the degree of achievement of the treatment on the basis of the above two targets.

ERI (erythropoietin responsiveness index) was defined as ESA dose per body weight per week for hemoglobin. The total amount of the ESA was defined as the total amount used of administration to a patient during 16 weeks. Hemoglobin was used as the average concentration during 16 weeks. Drug costs were based on drug insurance.

\subsection{Analysis Methods}

A statistical analysis of the study in the case of categorical data uses Fisher's exact test. The number of continuous data which cannot be assumed normality was analyzed by Mann-Whitney test. If normality of the data cannot be assumed, results are expressed as median (range). Analysis of the data was used as the SPSS ${ }^{\circledR}$ version 12.0 (SPSS Inc., Chicago, USA). P values less than 0.05 were deemed statistically significant.

\section{Results}

\subsection{Study Population}

Table 1 shows baseline characteristics for all patients. The median age in each group was 70 years old, 58 years old. Although patients with a diagnosis of diabetes were more in MPG-EPO group, it was not significantly different. Baseline hemoglobin levels before drug administration, approximately $9.4 \mathrm{~g} / \mathrm{dL}$ in both, did not differ between groups. Hematocrit also did not show a significant difference. Although there is a significant difference for the Serum ferritin $(P=$ 0.009), TIBC, TSAT, serum iron, i-PTH were no significant differences.

Table 1 Baseline characteristics of patients.

\begin{tabular}{|c|c|c|c|c|}
\hline & \multirow[b]{2}{*}{ Total $(n=22)$} & \multicolumn{2}{|c|}{ Treatment Group } & \multirow[b]{2}{*}{$P$-value } \\
\hline & & MPG-EPO $(n=13)$ & $\begin{array}{l}\text { DA } \\
(n=9)\end{array}$ & \\
\hline \multicolumn{5}{|l|}{ Gender, n (\%) } \\
\hline Male & $15(100.0)$ & $9(60.0)$ & $6(40.0)$ & 1.000 \\
\hline Female & $7(100.0)$ & $4(57.1)$ & $3(42.9)$ & \\
\hline Age (year) & $64.5(66.0)$ & $70.0(39.0)$ & $58.0(65.0)$ & 0.122 \\
\hline Body Weight (kg) & $60.3(40.0)$ & $60.0(29.0)$ & $64.0(28.1)$ & 0.857 \\
\hline Height (m) & $1.62(0.29)$ & $1.62(0.28)$ & $1.67(0.25)$ & 0.806 \\
\hline Serum Cr (mg/dL) & $6.69(9.98)$ & $6.51(7.97)$ & $7.04(9.51)$ & 0.601 \\
\hline eGFR-MDRD & $8.5(12.2)$ & $8.5(11.3)$ & $8.6(9.3)$ & 0.744 \\
\hline Hemoglobin (g/dL) & $9.5(2.6)$ & $9.4(1.9)$ & $9.5(2.3)$ & 0.987 \\
\hline $\operatorname{Hct}(\%)$ & $29.7(8.6)$ & $30.3(8.0)$ & $29.5(5.7)$ & 0.215 \\
\hline Serum Ferritin $^{1}(\mathrm{ng} / \mathrm{mL})$ & $306.9(5705.6)$ & $197.2(388.0)$ & $796.4(5575.6)$ & $0.009^{*}$ \\
\hline $\operatorname{TIBC}^{2}(\mu \mathrm{g} / \mathrm{dL})$ & $191.0(128.0)$ & $198.0(113.0)$ & $177.0(118.0)$ & 0.236 \\
\hline $\operatorname{TSAT}^{2}(\%)$ & $35.6(88.5)$ & $30.1(22.0)$ & $43.3(88.5)$ & 0.465 \\
\hline $\operatorname{Serum} \operatorname{Iron}^{2}(\mu \mathrm{g} / \mathrm{dL})$ & $76.0(161.0)$ & $68.0(46.0)$ & $87.0(161.0)$ & 0.409 \\
\hline $\mathrm{i}-\mathrm{PTH}^{3}(\mathrm{pg} / \mathrm{mL})$ & $204.3(360.4)$ & $211.2(360.4)$ & $172.2(203.0)$ & 0.589 \\
\hline \multicolumn{5}{|l|}{ Clinical condition $\mathrm{n}(\%)$} \\
\hline \multicolumn{5}{|l|}{ DM } \\
\hline Yes & $14(100.0)$ & $10(71.4)$ & $4(28.6)$ & 0.187 \\
\hline No & $8(100.0)$ & $3(37.5)$ & $5(62.5)$ & \\
\hline \multicolumn{5}{|l|}{ Hypertention } \\
\hline Yes & $22(100.0)$ & $13(59.1)$ & $9(40.9)$ & - \\
\hline \multicolumn{5}{|l|}{ Iron supplements } \\
\hline Yes & $16(100.0)$ & $8(50.0)$ & $8(50.0)$ & 0.333 \\
\hline No & $6(100.0)$ & $5(83.3)$ & $1(16.7)$ & \\
\hline
\end{tabular}

TIBC, total iron binding capacity; i-PTH, parathyroid hormone.

${ }^{1} 4$ cases with missing values are excluded; ${ }^{2} 5$ cases with missing values are excluded; ${ }^{3} 10$ cases with missing values are excluded.

* indicates $P$-value $<0.05$. 


\subsection{Usage}

\subsubsection{Administration Frequency}

The frequency of administration of MPG-EPO group was 4 times per 16 weeks, DA group was 12 times per 16 weeks. In the MPG-EPO groups, it showed a less frequency of administration (Table 2).

\subsubsection{Administration Dosage}

Total doses of MPG-EPO group were $485.0 \mu \mathrm{g}$, range was $120 \mu \mathrm{g}$ to $730 \mu \mathrm{g}$ and DA group were 300.0 $\mu \mathrm{g}$, ranging from $140 \mu \mathrm{g}$ to $570 \mu \mathrm{g}$. There was no significant difference (Table 2).
ERI represents the requirements of the ESA was in the MPG-EPO group and DA group each $7.8 \mathrm{U}$ per gram per deciliter per kg per week and $5.3 \mathrm{U}$ per gram per deciliter per kg per week. There was no significant difference between the two groups (Fig. 1).

\subsection{Efficacy}

\subsubsection{Hemoglobin Variation}

Hemoglobin variations in the evaluation period of administration of MPG-EPO group and DA group were both significantly higher than before administration.

Table 2 Description of prescribed medications.

\begin{tabular}{lll}
\hline & MPG-EPO & DA \\
\hline Total Dosage/16 weeks, $(\mu \mathrm{g})$ & & 140.0 \\
\hline Min & 120.0 & 570.0 \\
Max & 730.0 & $345.6(170.9)$ \\
Mean (SD) & $411.5(174.9)$ & $300.0(430.0)$ \\
Median (range) & $485.0(610.0)$ & 7 \\
\hline Number of Dosing/16 weeks, times & & 20 \\
\hline Min & 3 & $12.1(4.7)$ \\
Max & 7 & $12.0(13)$ \\
Mean (SD) & $4.5(1.2)$ & \\
Median (range) & $4.0(4)$ & \\
\hline
\end{tabular}

Min-minimum; Max-maximum; SD—standard deviation.

$P$-value 0.523 from Mann-Whitney test.

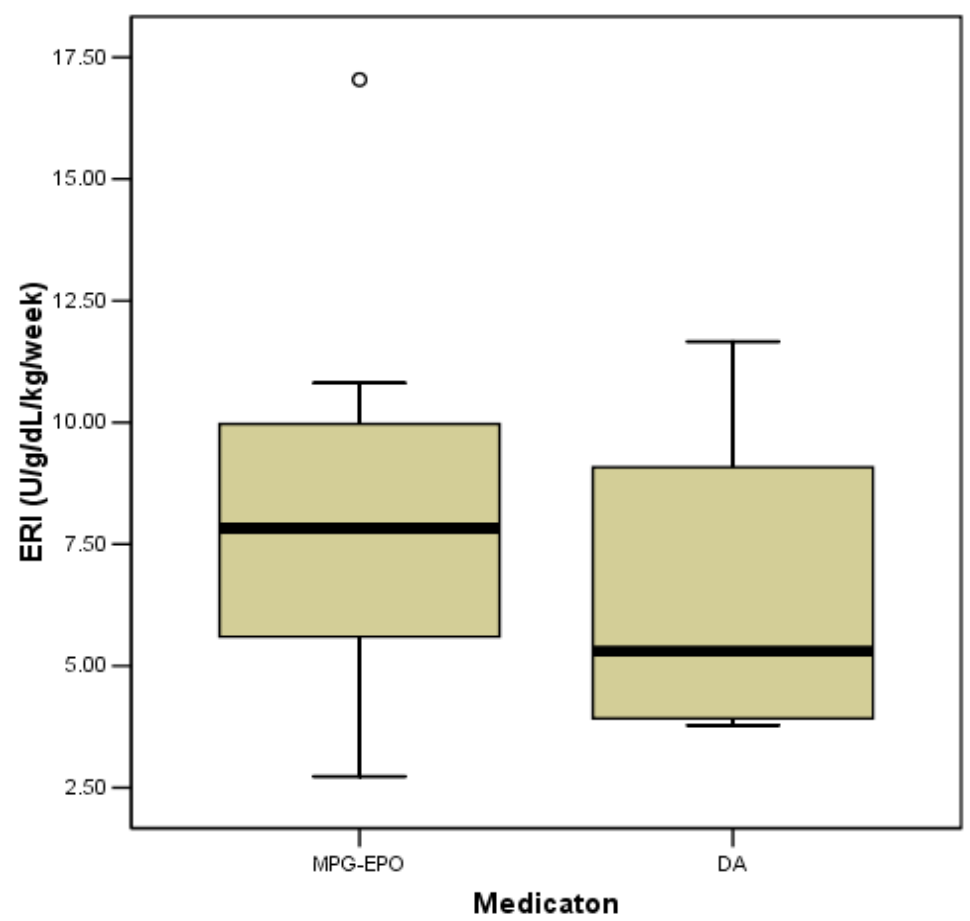

Fig. 1 Comparison of ERI between MPG-EPO and DA therapy group.

MPG-EPO group: 7.8 (14.3), DA group: 5.3 (7.9), $P$-value 0.481 from Mann-Whitney test. 
Hematocrit levels were similar increased rather than prior to administration in both groups (Table 3). The concentration of hemoglobin was increased by 4,8 weeks and 12, 16 weeks showed a tendency to be somewhat declined (Fig. 2). Variation of hemoglobin and hematocrit during of the DA group was showed a significant increase after 8, 16 weeks (Tables 3 and 4). The concentration of hemoglobin was showed a tendency to increase until after 4, 8, 12 weeks and was reduced after 16 weeks (Fig. 3).

\subsubsection{Hemoglobin Response Rate}

Hemoglobin response rate defined as the proportion of patients with hemoglobin concentration is increased more than $1.0 \mathrm{~g} / \mathrm{dL}$ after administration of the drug. The response rate of the MPG-EPO group administered after $4,8,12,16$ weeks was $30.8 \%$, $46.2 \%, 61.5 \%, 61.5 \%$, showed a tendency to gradually increase. While DA group was $22.2 \%, 77.8 \%, 66.7 \%$ and $66.7 \%$, after 8 weeks period showed the highest response rate. The mean response rate analyzed by comparing hemoglobin concentrations before drug administration was MPG-EPO group at $46.2 \%$, DA group at $77.8 \%$. DA group was higher but there was no significant difference (Table 5).

\subsubsection{Achievement of Hemoglobin}

Based on NKF-K/DOQI (national kidney foundation

Table 3 Change of hematocrit levels during study period.

\begin{tabular}{lllll}
\hline MPG-EPO & \multicolumn{3}{c}{ DA } \\
\hline Baseline & Hct, $(\%)$ & $P$-value $^{\mathrm{b}}$ & Hct, $(\%)$ & $P$-value \\
Week 4 & $30.3(8.0)$ & - & $29.5(5.7)$ & - \\
Week 8 & $31.6(9.0)$ & 0.104 & $30.4(7.7)$ & 0.156 \\
Week 12 & $31.6(10.8)$ & 0.414 & $34.8(9.3)$ & $0.020^{\text {b }}$ \\
Week 16 & $31.8(16.4)$ & 0.273 & $34.9(17.2)$ & 0.055 \\
\hline
\end{tabular}

Values are expressed as median (range).Value of each time point is compared with baseline data and $P$-values are from Wilcoxon's signed rank test.

* indicates $P$-value< 0.05 .

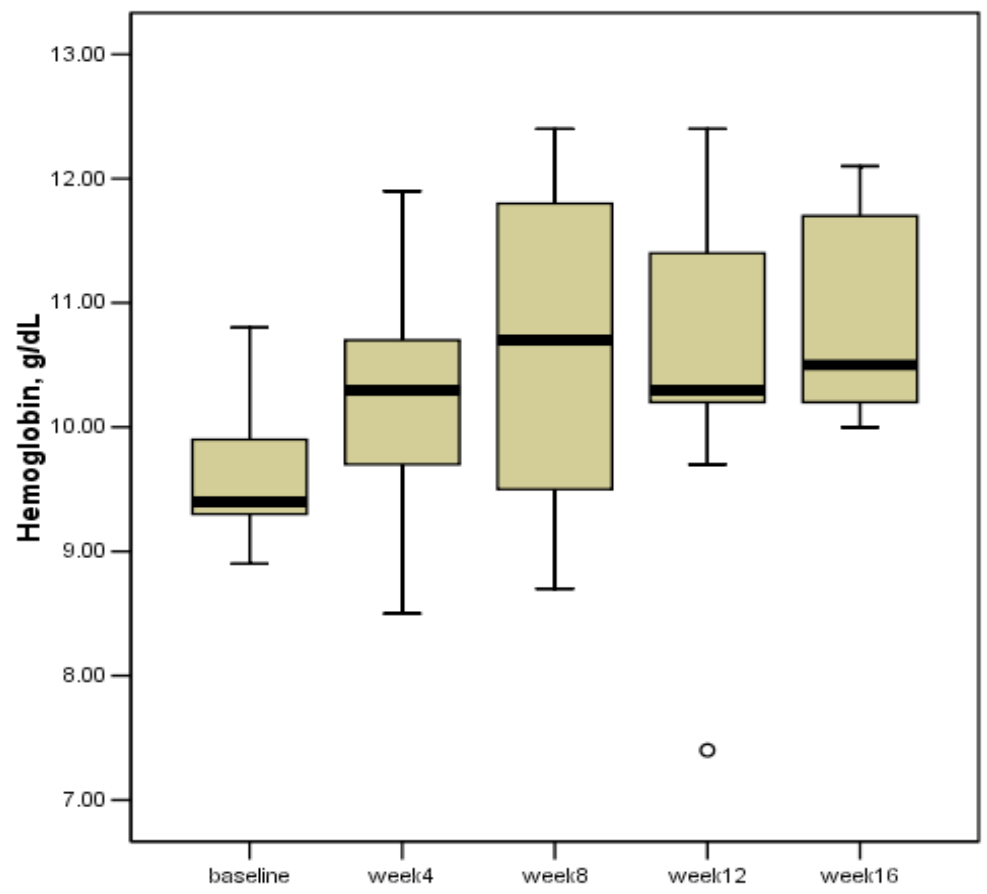

Fig. 2 Change of hemoglobin levels during study period in MPG-EPO therapy group $(n=13)$. 
Epoetin Beta and Darbepoetin Alfa with Hemodialysis Patients

Table 4 Comparison of Hb (hemoglobin) and Hct (hematocrit) levels between MPG-EPO and DA therapy group.

\begin{tabular}{lllll}
\hline Time (Week) & & MPG-EPO group $(n=13)$ & DA group $(n=9)$ & $P$-value \\
\hline 4 & Hb (g/dL) & $10.3(3.4)$ & $9.9(2.4)$ & 0.682 \\
& Hct (\%) & $31.6(9.0)$ & $30.4(7.7)$ & 0.568 \\
8 & Hb (g/dL) & $10.7(3.7)$ & $11.0(2.9)$ & 0.502 \\
& Hct (\%) & $31.6(10.8)$ & $34.8(9.3)$ & 0.284 \\
12 & Hb (g/dL) & $10.3(5.0)$ & $11.1(5.2)$ & 0.420 \\
& Hct (\%) & $31.8(16.4)$ & $34.9(17.2)$ & 0.659 \\
& Hb (g/dL) & $10.5(2.1)$ & $10.9(3.1)$ & 0.706 \\
& Hct (\%) & $31.7(10.5)$ & $33.1(10.8)$ & 0.695 \\
\hline
\end{tabular}

Values are expressed as median (range).

$P$-values are from Mann-Whitney test.

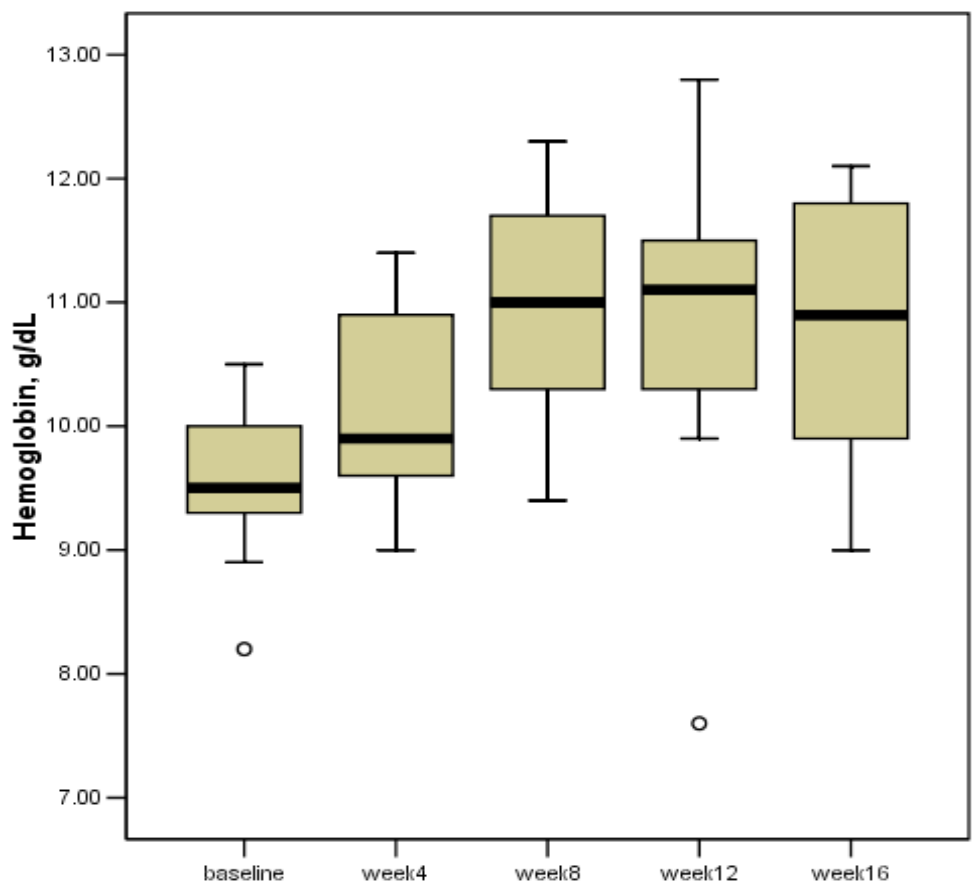

Fig. 3 Change of hemoglobin levels during study period in DA therapy group $(n=9)$.

Table 5 Comparison of hemoglobin responder rate between MPG-EPO and DA therapy group.

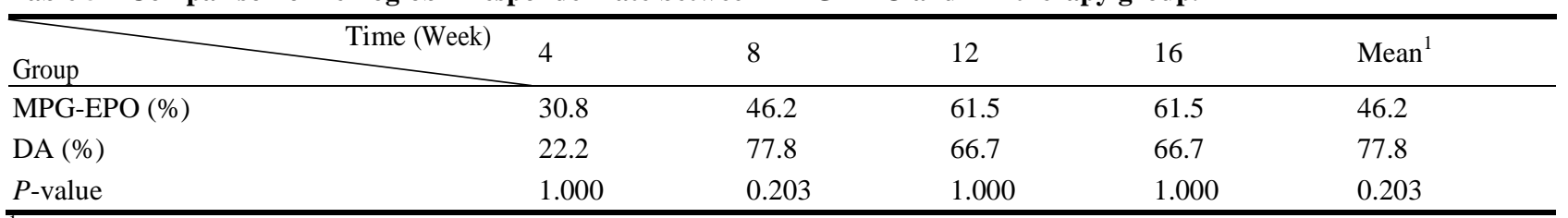

${ }^{\mathrm{T}}$ Evaluated from mean hemoglobin level of 4, 8, 12 and 16 weeks.

$P$-values are from Fisher's exact test

kidney disease outcome quality initiative) guideline, achievement was $23.1 \%, 15.4 \%, 7.7 \%, 30.8 \%$ administered after 4, 8, 12, and 16 weeks in MPG-EPO group. $22.2 \%, 44.4 \%, 33.3 \%, 33.3 \%$ in DA group. A higher rate in the DA group showed. Achievement by the average hemoglobin concentration was $38.5 \%$ in
MPG-EPO group, $22.2 \%$ in DA group based on NKF-K/DOQI guideline. MPG-EPO group was slightly higher but no significant difference (Table 6).

Based on Korea national health insurance criteria, achievement was $38.5 \%, 30.8 \%, 46.2 \%, 61.5 \%$ administered after 4, 8, 12, and 16 weeks in MPG-EPO 
group. $22.2 \%, 33.3 \%, 22.2 \%, 22.2 \%$ in DA group. Achievement by the average hemoglobin concentration was $30.8 \%$ in MPG-EPO group, $66.7 \%$ in DA group. There was no significant difference (Table 7).

\subsection{Adverse Events}

A patient $(7.7 \%)$ had diarrhea and 2 patients $(15.4 \%)$ had upper respiratory tract infection in MPG-EPO group in evaluation period. And no patient had an adverse event in DA group.

\subsection{Drug Cost}

The median of drug insurance cost was KRW495,274 in MPG-EPO group, KRW367,335 in DA group. MPG-EPO beta group was higher KRW127,939 but significant difference.

\section{Discussion}

This study showed that administration frequency was once a month in MPG-EPO group, three times a month in DA group. However, the total dosage of the two drugs was no significant difference. In the Fernando study, MPG-EPO and DA were administered once a month in the same interval, MPG-EPO therapy showed a higher efficacy [14]. In this study, patients were not administered with the same dosing interval. Therefore, efficacy when administered in the same dosing intervals could not be derived.

Hemoglobin concentration after administration of the drug was compared before administration was significantly increased in MPG-EPO and DA group administered after 4, 8, 12, 16 weeks. Variation of hemoglobin was increased up to 4,8 weeks but showed a tendency to decrease slightly 12, 16 weeks in MPG-EPO group. DA group showed a tendency to increase up to 12 weeks and to decrease after 16 weeks. This can be determined because the drug due to control of the dose or dose interval depending on the target range of hemoglobin according to the medication instructions. In Lee ji young study, patient seems to be a difference in reactivity for ESA [20]. The degree of absorption of the drug when injected subcutaneously every patient is different, and due to individual differences in reactivity to the administration frequency. The exact cause is difficult to cover in this study.

Achievement of treatment goals has a low tendency based on the NKF-K/DOQI therapeutic guidelines; 11.0 to $12.0 \mathrm{~g} / \mathrm{dL}$. This is a study conducted by

Table 6 Achievement of target hemoglobin based on NKF-K/DOQI guideline (11.0-12.0 g/dL).

\begin{tabular}{|c|c|c|c|c|c|}
\hline $\begin{array}{ll}\text { Achievement } & \text { Time (Week) } \\
\end{array}$ & 4 & 8 & 12 & 16 & Mean $^{1}$ \\
\hline \multicolumn{6}{|l|}{ MPG-EPO therapy } \\
\hline Yes, n $(\%)$ & $3(23.1)$ & $2(15.4)$ & $1(7.7)$ & $4(30.8)$ & $5(38.5)$ \\
\hline \multicolumn{6}{|l|}{ DA therapy } \\
\hline Yes, n (\%) & $2(22.2)$ & $4(44.4)$ & $3(33.3)$ & $3(33.3)$ & $2(22.2)$ \\
\hline$P$-value & 1.000 & 0.178 & 0.264 & 1.000 & 0.648 \\
\hline
\end{tabular}

${ }^{\mathrm{T}}$ Evaluated from mean hemoglobin level of 4, 8,12 and 16 weeks.

$P$-values are from Fisher's exact test.

Table 7 Achievement of hemoglobin based on the Korean National Health Insurance Criteria (10.0-11.0 g/dL).

\begin{tabular}{llllll}
\hline \multicolumn{1}{c}{ Time (Week) } & 4 & 8 & 12 & 16 & Mean \\
Achievement & $5(38.5)$ & $4(30.8)$ & $6(46.2)$ & $8(61.5)$ & $4(30.8)$ \\
$\begin{array}{l}\text { MPG-EPO Therapy } \\
\begin{array}{l}\text { Yes, n (\%) } \\
\text { DA therapy }\end{array} \\
\text { Yes, n (\%) }\end{array}$ & $2(22.2)$ & $3(33.3)$ & $2(22.2)$ & $2(22.2)$ & $6(66.7)$ \\
$P$-value & 0.648 & 1.000 & 0.380 & 0.099 & 0.192 \\
\hline
\end{tabular}


collecting data from patients treated according to national insurance standards. In most cases, in consideration of the economic situation of the patient, dosage of the ESA was reduced based on the hemoglob in concentration $11.0 \mathrm{~g} / \mathrm{dL}$, or stopping the administration. Due to the ESA interruption, loss of erythropoietin precursor period is extended. Also the period of maintaining low hemoglobin compared to the reference target can be long and amplify the hemoglobin cycling [19]. In addition, there are reports that concentration of hemoglobin rapidly changing may increase morbidity and mortality in ESRD patients. Analysis for morbidity and survival of the administration of ESA treatment for the anemia of chronic renal failure in hemodialysis patients and for evaluation the quality of life will be a follow-up study conducted.

In the present study, the drug costs were slightly higher in the MPG-EPO group. Drugs can be used by subcutaneous injection [16]. Patients have been prescribed to themselves abdomen, arms, thigh. Cost comparison of the drug was applied only to simple drug costs in this study. Administration fee, drug management storage fee, medical fee, etc. did not take into account costs. Because all drug costs calculated in the insurance price, normal price according to the hemoglobin value will have to be adjusted.

\section{Conclusion}

Use of MPG-EPO is as effective and safe as DA managing renal anemia in hemodialysis patients. MPG-EPO's extended administration interval improves patient's compliance and enables effective anemia treatment. Therefore, this study can contribute to drug selection for the treatment of anemia of hemodialysis patients. Limitation is that the study was conducted retrospectively recorded by clinical examination performed on medical records. Only clinical examination data in medical records could be reviewed. In spite of this figure shows the difference between the absolute value of the test, patients with less number is statistically in significant results came out. However clinically, there are parts that can be interpreted as a meaningful result. The clinical significance of this effect must be determined in larger, long term trials.

\section{References}

[1] Ohashi, N., Sakao, Y., Yasuda, H., Kato, A., and Fujigaki, Y. 2012. "Methoxy Polyethylene Glycol-Epoetin Beta for Anemia with Chronic Kidney Disease." International Journal of Nephrology and Renovascular Disease 5: 53-60.

[2] Go, A. S., Chertow, G. M., Fan, D., McCulloch, C. E., and Hsu, C. Y. 2004. "Chronic Kidney Disease and the Risks of Death, Cardiovascular Events, and Hospitalization." New England Journal of Medicine 351 (13): 1296-305.

[3] KDOQI, and National Kidney Foundation. 2006. "KDOQI Clinical Practice Guidelines and Clinical Practice Recommendations for Anemia in Chronic Kidney Disease." American Journal of Kidney Diseases 47 (5 Suppl 3): S11-145.

[4] Halstenson, C. E., Macres, M., Katz, S. A., Schnieders, J. R., Watanabe, M., Sobota, J. T., and Abraham, P. A. 1991. "Comparative Pharmacokinetics and Pharmacodynamics of Epoetin Alfa and Epoetin Beta." Clinical Pharmacology and Therapeutics 50 (6): 702-12.

[5] Robinson, D. M., and Easthope, S. E. 2005. "Darbepoetin Alfa: Its Use in Anemia Associated with Chronic Kidney Disease." Biodrugs 19 (5): 327-43.

[6] Padhi, D., Ni, L., Cooke, B., Marino, R., and Jang, G. 2006. "An Extended Terminal Half-Life for Darbepoetin Alfa: Results from a Single-Dose Pharmacokinetic Study in Patients with Chronic Kidney Disease Not Receiving Dialysis."Clinical Pharmacokinetics 45 (5): 503-10.

[7] Macdougall, I. C., Gray, S. J., Elston, O., Breen, C., Jenkins, B., Browne, J., and Egrie, J. 1999. "Pharmacokinetics of Novel Erythropoiesis Stimulating Protein Compared with Epoetin Alfa in Dialysis Patients." Journal of the American Society of Nephrology 10 (11): 2392-5.

[8] Lee, I. H., Shin, S. K., Kang, S. W., Noh, H. J., Seo, B. J., Park, H. C., Choi, K. H., Ha, S. K., Lee, H. Y., Han, D. S., Lee, E. Y., Kang, D. H., Choi, G. B., and Yoon, K. I. 1998. "Phase III Clinical Trial Evaluating Efficacy and Safety of Recombinant Human Erythropoietin (Epokine(R)) in Hemodialysis Patients." Korean Journal of Nephrology 17 (3): 466-75.

[9] Kruep, E. J., and Basskin, L. E. 2005. "Cost-Minimization Analysis of Darbepoetin Alfa versus Epoetin Alfa in the Hospital Setting." American Journal of Health-System 

Epoetin Beta and Darbepoetin Alfa with Hemodialysis Patients

Pharmacy 62 (24): 2597-603.

[10] Nissenson, A. R., Swan, S. K., Lindberg, J. S., Soroka, S. D., Beatey, R., Wang, C., Picarello, N., McDermott-Vitak, A., and Maroni, B. J. 2002. "Randomized, Controlled Trial of Darbepoetin Alfa for the Treatment of Anemia in Hemodialysis Patients." American Journal of Kidney Diseases 40 (1): 110-8.

[11] Canaud, B., Mingardi, G., Braun, J., Aljama, P., Kerr, P. G., Locatelli, F., Villa, G., Van Vlem, B., McMahon, A. W., Kerloeguen, C., and Beyer, U. 2008. "Intravenous C.E.R.A. Maintains Stable Haemoglobin Levels in Patients on Dialysis Previously Treated with Darbepoetin Alfa: Results from STRIATA, a Randomized Phase III Study." Nephrology Dialysis and Transplantation 23 (11): 3654-61.

[12] Sulowicz, W., Locatelli, F., Ryckelynck, J. P., Balla, J., Csiky, B., Harris, K., Ehrhard, P., and Beyer, U. 2007. "Once-Monthly Subcutaneous C.E.R.A. Maintains Stable Hemoglobin Control in Patients with Chronic Kidney Disease on Dialysis and Converted Directly from Epoetin One to Three Times Weekly." Clinical Journal of the American Society of Nephrology 2 (4): 637-46.

[13] Spinowitz, B., Coyne, D. W., Lok, C. E., Fraticelli, M., Azer, M., Dalal, S., Villa, G., Rosansky, S., Adamis, H., and Beyer, U. 2008. "C.E.R.A. Maintains Stable Control of Hemoglobin in Patients with Chronic Kidney Disease on Dialysis When Administered Once Every Two Weeks.” American Journal of Nephrology 28 (2): 280-9.

[14] Carrera, F., Lok, C. E., de Francisco, A., Locatelli, F., Mann, J. F., Canaud, B., Kerr, P. G., Macdougall, I. C., Besarab, A., Villa, G., Kazes, I., Van Vlem, B., Jolly, S., Beyer, U., and Dougherty, F. C. 2010. "Maintenance Treatment of Renal Anaemia in Haemodialysis Patients with Methoxy Polyethylene Glycol-Epoetin Beta versus Darbepoetin Alfa Administered Monthly: A Randomized
Comparative Trial." Nephrology Dialysis and Transplantation 25 (12): 4009-17.

[15] Fliser, D., Kleophas, W., Dellanna, F., Winkler, R. E., Backs, W., Kraatz, U., Fassbinder, W., Wizemann, V., and Strack, G. 2010. "Evaluation of Maintenance of Stable Haemoglobin Levels in Haemodialysis Patients Converting from Epoetin or Darbepoetin to Monthly Intravenous C.E.R.A.: the MIRACEL Study." Current Medical Research and Opinion 26 (5): 1083-9.

[16] MIRCERA®. 2010. MIRCERA®: Methoxy Polyethylene Glycol-Epoetin Beta [Product Information]. Dee Why, Australia: Roche, Accessed March 23, 2012. http://www.rocheaustralia.com/fmfiles/re7229005/downl oads/anaemia/mircera-pi. pdf.

[17] Roche. 2012. Micera ${ }^{\circledR}$ Solution for Injection in Pre-Filled Syringe [Summary of Product Characteristics]. Welwyn Garden City: Roche Ltd, Accessed February 21, 2012. http://www.medicines.org.uk/emc/medicine/19960/SPC/.

[18] Oh, J., Joo, K. W., Chin, H. J., Chae, D. W., Kim, S. G., Kim, S. J., Chung, W. K., Huh, W., Oh, H. Y., Yang, C. W., and Kim, S. 2010. "Mircera Corrects Anemia in Korean Patients with Chronic Kidney Disease on Dialysis: Results from a Randomized Controlled Multicenter Study." Korean Journal of Nephrology 29 (1): S413.

[19] Park, S. K., Hwang, K. S., Park, J. S., Lee, C. H., Kang, C. M., and Kim, G. H. 2011. "Hemoglobin Variability Associated with Different Erythropoiesis Stimulating Agents in Hemodialysis Patients." Korean Journal of Nephrology 30 (1): 41-7.

[20] Lee, J. Y., Byun, S. W., Yeo, Y. S., Yang, W. S., Park, S. K., Park, J. S., and Chang, J. W. 2009. "Comparison of Erythropoietic Effect between Epoetin-Alpha and Darbepoetin-Alpha in Hemodialysis Patients: A Randomized Crossover Study." Korean Journal of Nephrology 28 (5): 450-5. 